NBER WORKING PAPER SERIES

SEASONAL FLUCTUATIONS AND THE LIFE CYCLE-PERMANENT INCOME

MODEL OF CONSUMPTION

Jeffrey A. Miron

Working Paper No. 1845

NATIONAL BUREAU OF ECONOMIC RESEARCH

1050 Massachusetts Avenue

Cambridge, MA 02138

February 1986

The research reported here is part of the NBER's research program in Financial Markets and Monetary Economics. Any opinions expressed are those of the author and not those of the National Bureau of Economic Research. 
NBER Working Paper \#1845

February 1986

\title{
Seasonal Fluctuations and the Life Cycle-Permanent Income Model of Consumption
}

\begin{abstract}
Recent empirical work has found that both aggregate and micro data reject the rational expectations version of the Life Cycle-Permanent Income model of consumption. This paper examines a new possible explanation for the rejections: the treatment of seasonal fluctuations. There are substantial seasonal fluctuations in consumption purchases, but no previous paper has determined whether these fluctuations are consistent with the Life Cycle-Permanent Income model. The results in this paper show that when the seasonal fluctuations in consumption purchases are included in an analysis of the Life Cycle-Permanent Income model there is no evidence in the aggregate data against the model. The estimates of the parameters of agents' utility functions obtained here are plausible, and the data do not reject the overidentifying restrictions on the model.
\end{abstract}

Jeffrey A. Miron

Department of Economics

The University of Michigan

Ann Arbor, MI 48109

(313) 764-2363 


\section{Introduction}

The Life Cycle-Permanent Income model of consumption behavior has been the standard framework for analyzing consumption since the seminal work by Modigliani and Friedman. ${ }^{1}$ Recently, however, the ability of the model to fit the data has been called into question. A sequence of papers, beginning with that by Hall (1978), has found that both aggregate and micro time series data reject certain implications of the rational expectations version of the model. ${ }^{2}$ This rejection applies both to the joint behavior of consumption and income and to the joint behavior of consumption and asset returns. ${ }^{3}$ It is independent of whether labor supply is included in the model, and it is robust with respect to choice of utility function, data frequency, and consumption category. ${ }^{4}$

Two main explanations have been proposed for these rejections. ${ }^{5}$ The most prominent is that some economic agents are liquidity constrained so that they cannot adjust their consumption over time in the way implied by the model. The other main line of argument is that the observed rejections are rejections of the functional forms assumed for preferences in existing work but not necessarily rejections of the Life Cycle-Permanent Income model. Both explanations have received some support from the data. Several studies of micro data show that the consumption behavior of low wealth consumers generally does not satisfy the model while that of high wealth consumers does. ${ }^{6}$ Browning (1983) shows that a non-parametric test of the Life Cycle-Permanent Income model on British data does not reject it for substantial sections of the post war period.

Neither explanation for the recent rejections of the model is entirely satisfactory, however. The proponents of the 'liquidity constraints' hypothesis have not presented a model of behavior under liquidity constraints that rationalizes the particular types of rejections found in the data. Further, low wealth consumers account for too small a portion of total consumption purchases for their consumption behavior to explain the rejection of the model at the aggregate level. The nonparameteric approach is unsatisfactory because the periods for which it breaks down are precisely those for which one would like to have a good model $(1974,1979)$. Also, the utility functions implied by the non-parametric approach may be very complicated. Unless a relatively tractable parameterization of the Life Cycle-Permanent Income model is consistent with the data, the model is not particularly useful even if correct in some complicated way.

This paper examines a new possible explanation for the recent rejections of the Life CyclePermanent Income model: the treatment of seasonal fluctuations. There are substantial seasonal fluctuations in aggregate consumption purchases, but no previous paper has determined whether these fluctuations are consistent with the Life Cycle-Permanent Income model. ${ }^{7}$ Seasonal fluctua-

1 See Modigliani and Brumberg (1954), Ando and Modigliani (1963), and Friedman (1957).

2 See Hall (1978), Sargent (1978), Flavin (1981), Hayashi (1982), Mankiw (1982,1983), Bernanke (1982), Hansen and Singleton (1982,1983), Eichenbaum, Hansen and Singleton (1984), and Mankiw, Rotemberg, and Summers (1984) for examples of rejections of the aggregate data. See Hall and Mishkin (1982), Zeldes (1984), Runkle (1983), Hayashi (1984) and Shapiro (1984) for results on micro data.

3 Flavin (1981), for example, examines the joint relation between consumption and income, while Hansen and Singleton (1983) examine the relation between consumption and asset returns.

4 Mankiw, Rotemberg and Summers (1984) and Eichenbaum, Hansen and Singleton (1984) examine models that are non-separable in consumption and leisure. Flavin (1981) uses quarterly data while Hansen and Singleton (1983) use monthly data; Flavin (1981) uses quadratic utility while Hansen and Singleton (1983) employ constant relative risk aversion. Bernanke $(1984)$ and Mankiw $(1982,1983)$ examine durable goods as well as non-durables and services.

5 See King (1983) for a detailed review of the evidence on the Life Cycle-Permanent Income model.

6 See Hall and Mishkin (1982), Runkle (1983), and Zeldes (1984).

7 Hall $(1978,1980)$, Flavin (1981), Bernanke (1982), and Mankiw, Rotemberg, and Summers (1984) use seasonally adjusted quarterly dat a; Eichenbaum, Hansen and Singleton (1984) and Hansen and Singleton $(1982,1983)$ use seasonally adjusted monthly data; Hall (1982) and Mankiw $(1982,1983)$ use fourth quarter only seasonally adjusted data; and Hayashi (1982) uses annual data. A partial exception to this statement is Sargent (1978), 
tions, however, are likely to be well described by a rational expectations, equilibrium model because they are predictable. This means that a substantial part of consumption behavior may fit the Life Cycle-Permanent Income model even if the conclusions in previous work about the business cycle fluctuations are correct. Further, the seasonal adjustment procedures currently in use introduce measurement errors that will tend to produce rejections of the model even when it accurately describes the data. ${ }^{8}$ Thus previous papers may have reached biased conclusions about the business cycle fluctuations in consumption due to the exclusion of seasonal fluctuations.

The results in this paper show that when the seasonal fluctuations are included in an analysis of the Life Cycle-Permanent Income model there is no evidence in the aggregate data against the model. ${ }^{9}$ The estimates of the parameters of agents' utility functions obtained here are plausible, and the data do not reject the overidentifying restrictions on the model as they have in previous papers. The results provide no evidence of liquidity constraints at seasonal or non-seasonal frequencies. They do provide a tightly parameterized model of preferences.

The paper is organized as follows. It begins in Section 2 by examining stylized facts about the seasonal fluctuations in aggregate consumption purchases. These facts show that the seasonal fluctuations are large and that therefore including them in an analysis of the Life Cycle-Permanent Income model may alter assessment of it substantially. Section 3 presents a rational expectations, Life Cycle-Permanent Income model of intertemporal consumption behavior that is capable of explaining both the seasonal and non-seasonal fluctuations in consumption purchases. This model implies the existence of an equilibrium pricing function that relates the seasonally unadjusted values of consumption and real asset returns to seasonal shocks to preferences and technology. Section 4 reports estimates and tests of the model. Section 5 concludes the paper by discussing implications of the results for the study of equilibrium models of the business cycle.

\section{Stylized Facts About the Seasonality of Aggregate Consumption Purchases}

This section examines stylized facts about the seasonal fluctuations in aggregate consumption purchases. The main purpose is to show that these fluctuations are large and that therefore including them can have a significant impact on estimation results. In addition, the section establishes facts about the seasonally unadjusted data on consumption purchases that a coherent model should be able to explain.

An appendix describes the construction of the data. The Department of Commerce does not publish seasonally unadjusted data on real consumption purchases, but it is possible to construct such data by deflating seasonally unadjusted series on nominal purchases by seasonally unadjusted components of the Consumer Price Index. ${ }^{10}$ This procedure is analagous to the one used by the Department of Commerce to construct seasonally adjusted data.

who uses seasonally unadjusted U.S. data. He does not, however, examine the seasonal coefficients that he estimates. Similarly, Davidson and Hendry (1981), Davidson, Hendry, Srba and Yeo (1978), and Hendry and Von Ungern-Sternberg (1980) use seasonally unadjusted U.K. data, but they do not study the economic significance of the seasonal coefficients they estimate. Heien (1983) analyzes the seasonality of aggregate consumption data but in a static framework. Hayashi (1984) uses seasonally unadjusted panel data to study the Permanent Income Hypothesis for Japanese data. All panel data studies for the U.S. have used annual data.

8 Appendix B of my Ph.D. thesis (Miron (1984)) shows this explicitly. The reason is that the Census X11 seasonal adjustment procedure makes the adjusted data a two sided filter of the unadjusted series. This practice guarantees that the key orthogonality condition implied by the model will be violated by the seasonally adjusted data. Data adjusted by the seasonal dummy technique will also tend to reject the model if it contains fundamental non-linearities.

9 By "inclusion of seasonal fluctuations," I mean using seasonally unadjusted data and allowing for seasonals in preferences and technology.

10 Sargent (1978) use this procedure to compute seasonally unadjusted real values of consumption and GNP. 
For the purpose of presenting stylized facts I assume that the data on consumption purchases are approximately described by the following model: ${ }^{11}$

$$
\begin{gathered}
Y_{t}=S_{t} T_{t} Z_{t} \\
S_{t}=\exp \left(a^{\prime} d_{t}\right) \\
T_{t}=\exp \left(b t+c t^{2}\right)
\end{gathered}
$$

where

$Y_{t}$ is an economic time series,

$S_{t}$ is the seasonal component of the series,

$T_{t}$ is the trend component of the series,

$Z_{t}$ is the business cycle component of the series,

$d_{t}$ is a vector of seasonal dummies, and

$a^{\prime}$ is a coefficient vector.

Equations (1)-(3) imply that

$$
\ln Y_{t}=a^{\prime} d_{t}+b t+c t^{2}+\ln Z_{t}
$$

It follows from (4) that if $a_{i}$ is the coefficient on the ith seasonal dummy, then $Y_{t}$ is on average $a_{i}$ percent higher in season $i$ than during the rest of the year.

Table 1 presents estimates of the seasonal factors in thirteen categories of real consumption purchases. The amount of seasonal variation in many of the components is striking. For example, the amplitude of the seasonal cycle in purchases of Motor Vehicles and Parts is more than $16 \%$, while that in purchases of Clothing and Shoes is over $41 \%$. The table also shows the $R^{2}$ 's from the regressions that were used to estimate the seasonal factors. The series were detrended before the seasonal patterns were estimated, so these $R^{2}$ 's are estimates of the percentage of the non-trend variation due to seasonality. For most of these series the percentage exceeds $40 \%$ and for several it exceeds $\mathbf{7 0 \%}$. Thus seasonal fluctuations account for a quantitatively important part of the total variation in consumption purchases.

The results indicate that, if these seasonal fluctuations are to be the outcome of an equilibrium process, then there must be seasonal shocks to preferences and/or technology that imply seasonal shocks to the equilibrium pricing function relating aggregate consumption quantities to intertemporal prices. The model presented below allows for seasonal shocks to both preferences and technology, and the estimation results provide a means of characterizing how much of the seasonality documented in Table 1 is due to each of these sources. In the remainder of this section, I discuss at an intuitive level some additional aspects of the results in Table 1.

There are large increases during the fourth quarter of purchases of Clothing and Shoes, Other Durables (which includes durable toys such as bicycles), and Other Non-durables (which includes non-durable toys). These increases are probably due to Christmas, which is plausibly interpreted as a shock to preferences.

The results in the table suggest that the weather is an important source of seasonal shocks to the economy. Purchases of Fuel Oil and Coal and Electricity and Gas increase in the first quarter (winter) and decrease in the third quarter (summer), probably as the result of the quarterly changes in temperature. Purchases of Transportation Services and Gasoline and Oil, on the other hand, decrease in winter and increase in summer, which probably indicates that good weather makes it

11 I have also computed seasonal factors under the assumption that the first difference of the log of consumption purchases equals a seasonal plus a stationary series. The estimates of seasonal factors obtained from that model were qualitatively similar to those presented here. See Nelson and Plosser (1982) for a discussion of trends versus random walks in aggregate data. 
Table 1: Seasonal Patterns in Real Consumption Purchases

\begin{tabular}{|c|c|c|c|c|c|}
\hline & $Q_{1}$ & $Q_{2}$ & $Q_{3}$ & $Q_{4}$ & $R^{2}$ \\
\hline Consumption & -4.76 & -.12 & -1.14 & 6.01 & .47 \\
\hline Durables & -11.08 & 2.50 & -2.44 & 10.99 & .40 \\
\hline Motor Vehicles and Parts & -7.30 & 9.23 & 1.32 & -3.25 & .07 \\
\hline Furniture and Appliances & -14.26 & -3.18 & -1.31 & 18.76 & .68 \\
\hline Other Durables & -18.78 & -2.98 & -8.27 & 30.04 & .77 \\
\hline Non-durables & -8.28 & -.96 & -1.30 & 10.55 & .70 \\
\hline Food & -6.03 & .15 & 1.60 & 4.27 & .24 \\
\hline Clothing and Shoes & -17.21 & -.38 & -6.98 & 24.55 & .87 \\
\hline Gasoline and Oil & -8.76 & 2.85 & 5.35 & .57 & .17 \\
\hline Fuel Oil and Coal & 32.05 & -17.12 & -31.76 & 16.82 & .76 \\
\hline Other Non-durables & -9.80 & -.77 & -1.81 & 12.38 & .94 \\
\hline Services & .71 & .01 & .15 & -.58 & .00 \\
\hline Housing & -.15 & .01 & .31 & -.15 & .00 \\
\hline Household Operations & 11.25 & -3.13 & -7.57 & -.57 & .49 \\
\hline Electricity and Gas & 27.39 & -9.45 & -16.39 & -1.55 & .90 \\
\hline Other Household Operation & -.62 & .06 & .05 & .50 & .02 \\
\hline Transportation & -3.48 & 1.34 & 2.92 & -.78 & .14 \\
\hline Other Services & -1.76 & .81 & 1.74 & -.79 & .19 \\
\hline
\end{tabular}


more desirable to travel. Weather may affect economic activity either through tastes or technology, but the data in the table seem more suggestive of preferences shocks as the reasons for the particular seasonal patterns shown in the table. The fact that the weather appears to affect seasonal economic activity is interesting because the weather can have unanticiapted effects as well as seasonal ones.

The results also show that purchases of durable components of consumption display much larger seasonal fluctuations than non-durable components. ${ }^{12}$ For example, the amplitude of the cycle in Durables is $22.07 \%$ while that in Services is only $1.29 \%$. There are several possible explanations. One is that consumers are more willing to tolerate fluctuations in their consumption of durables than in their consumption of services. Alternatively, there may be larger seasonals in preferences for durable goods than for non-durable goods.

These possibilities, of course, could just as easily explain different seasonal patterns in different non-durable goods as the differences between durables and non-durables. An explanation that focusses explicitly on the durability of durables is that in order to change the stock of a durable good by a given percentage it is necessary to make a larger percentage purchase of the durable good. Therefore purchases of durables should be more seasonal than those of non-durables even if preferences for these goods are identical. ${ }^{13}$

The stylized facts presented above establish that seasonal fluctuations account for a substantial part of the total variation in consumption purchases. This means that inclusion of the seasonal fluctuations can have a significant impact on analyses of the Life Cycle-Permanent Income model. The facts also show additional aspects of the seasonal patterns in consumption that it is important for a model to be able to explain. These are that there are probably substantial seasonal shocks to preferences, that the weather appears to cause some of these shocks, and that the seasonal fluctuations in durables are greater than those in non-durables.

\section{A Model of Intertemporal Consumption Choice}

This section presents a rational expectations, Life Cycle-Permanent Income model of consumption that can explain both the seasonal and non-seasonal fluctuations in aggregate consumption purchases. The model is a representative consumer model that generates an equilibrium pricing function relating consumption purchases to real asset returns. ${ }^{14}$ The particular model proposed here generalizes those in previous papers by allowing for seasonal shocks to preferences and technology. In the discussion below, I first derive the implications of the model for an individual consumer and interpret the model in that context. I then discuss under what conditions the model implies a well defined aggregate relation between consumption and asset returns. The interpretation of this relation turns out to be an equilibrium pricing function of the kind derived by Lucas (1978).

\section{A. The Individual Consumer}

The representative consumer chooses the time path for consumption that solves

$$
\max \mathrm{E}_{t} \sum_{s=0}^{\infty} \beta^{s} U\left(C_{t+s}\right)
$$

$C_{t}$ is the flow of consumption services the consumer receives in period $t, U(\cdot)$ is the period utility function, $\beta$ is a subjective discount factor, and $E_{t}$ denotes the rational expectation based on information available at time $t$. The utility function assumed in (5) is additively separable over time

12 I am including Clothing and Shoes as a durable good.

13 Mankiw (1983) has proposed this explanation for the volatility of durables purchases over the business cycle. Mishkin (1976) argues that it is due to the illiquidity of durables as assets.

14 See Eichenbaum and Hansen (1983) for an analysis of aggregate consumption that does not employ the representative consumer paradigm. 
and implicitly additively separable in consumption and leisure. Both separability assumptions are maintained in most empirical work because they simplify estimation considerably. ${ }^{15}$

The flow of consumption services received in each period depends on the stock of consumption goods owned by the consumer and on a set of exogenous variables:

$$
C_{t}=F\left(K_{t}, X_{t}\right)
$$

$K_{t}$ is a $Q \times 1$ vector of the stocks of consumption goods and $X_{t}$ is an $S \times 1$ vector of variables that affects the flow of consumption services obtained from any level of $K_{t}$. The function $F(\cdot)$ can be thought of as the production function consumers use to transform consumption goods into consumption services, as in Lancaster (1966) and Becker and Stigler (1977), or as part of preferences. The $X_{t}$ variables are then interpreted as shocks to consumers' production functions/preferences. The consumer does not control $X_{t}$.

The consumer does control the stock of existing consumption goods by making purchases of new consumption goods. The stock of existing goods is related to the flow of new purchases, $I_{t}$, by

$$
K_{t}=(1-d) K_{t-1}+I_{t}
$$

where $I_{t}$ is a $Q \times 1$ vector of the purchases of new consumption goods, ' 1 ' is the $Q \times Q$ identity matrix, and $d$ is a $Q \times Q$ diagonal matrix in which the qth diagonal element is the depreciation rate of the $q t h$ good. For non-durable goods, $d_{q}=1$ so $K_{t}^{q}=I_{t}^{q}$.

The first order conditions for the consumer's optimal consumption plan consist of stochastic Euler equations. ${ }^{16}$ There are many different types of Euler equations for the problem specified in (5)-(7); this paper examines two types that can be written in relatively intuitive forms. These first-order conditions follow from the assumption that the consumer has access to a capital market in which he can freely trade various financial assets. The first-order conditions derived and tested below must hold with respect to all such assets; the deriviations, however, are carried out only for a single asset for simplicity of presentation. ${ }^{17}$

The first type of first-order condition says that the marginal utility of increasing purchases of a non-durable good must be the same as the expected marginal utility of investing the cost of that unit and then purchasing the good next period with the investment plus accrued return:

$$
\frac{\partial U\left(C_{t}\right)}{\partial I_{t}^{q}}=\mathrm{E}_{t} \beta \frac{\partial U\left(C_{t+1}\right)}{\partial I_{t+1}^{q}}\left(1+r_{t+1}^{q}\right)
$$

where

$$
1+r_{t+1}^{q}=\frac{1+i_{t+1}}{p_{t+1}^{q} / p_{t}^{q}}
$$

In (8), $I_{t}^{q}$ denotes purchases of a non-durable good, $p_{t}^{q}$ is the nominal price of that good, and $i_{t+1}$ is the nominal return on any financial asset between $t$ and $t+1$. The quantity $\left(1+r_{t+1}^{q}\right)$ is therefore the real return measured in terms of the $q t h$ good, i.e., the rate at which the consumer can trade non-durable consumption this period for non-durable consumption next period.

\footnotetext{
15 The papers by Mankiw, Rotemberg and Summers (1984) and Eichenbaum, Hansen and Singleton (1984) indicate that relaxation of these two assumptions does not qualitatively change the result that the seasonally adjusted data reject the Life Cycle-Permanent Income Model.

16 There are also non-stochastic Euler equations. This paper does not examine those equations.

17 See Grossman and Shiller (1981), Shiller (1982), and Hansen and Singleton $(1982,1983)$ for analyses that explicitly consider the availability of many financial assets.
} 
The second type of first order condition says that the marginal utility of increasing purchases of a durable good must be the same as the expected marginal utility of investing the cost of the durable, using part of the return to replenish the stock of the durable good next period (so that the stock is unchanged in all future periods) and spending the rest on a non-durable good:

$$
\frac{\partial U\left(C_{t}\right)}{\partial I_{t}^{j}}=\mathrm{E}_{t} \beta \frac{\partial U\left(C_{t+1}\right)}{\partial I_{t+1}^{q}}\left(1+r_{t+1}^{j, q}\right)
$$

where

$$
1+r_{t+1}^{j, q}=\frac{p_{t}^{j}\left(1+i_{t+1}\right)-(1-d) p_{t+1}^{j}}{p_{t+1}^{q}}
$$

$I_{t}^{j}$ denotes purchases of a durable good and $I_{t+1}^{q}$ purchases of a non-durable. The quantity $\left(1+r_{t+1}^{j, q}\right)$ is the rate at which the consumer can carry out in the marketplace the trade described above.

The two first-order conditions determine the rate at which an individual consumer will purch ase non-durables and adjust the level of stocks of durables. The consumer alters the desired rate of growth and levels of these variables in response to movements in asset returns. We can see this more clearly by imposing at this point the assumptions about functional forms that will be made in order to parameterize the model for estimation.

The period utility function, $U(\cdot)$, is additively separable in the utility from the $Q$ different consumption services, and the $q$ th sub-utility function is of the constant intertemporal elasticity of substitution form:

$$
\begin{gathered}
U\left(C_{t}\right)=\sum_{q=1}^{Q} U_{q}\left(C_{t}^{q}\right) \\
U_{q}\left(C_{t}^{q}\right)=\frac{\left(C_{t}^{q}\right)^{1-\gamma_{q}}}{1-\gamma_{q}} \quad q=1, \ldots, Q
\end{gathered}
$$

In (13), $\gamma_{q}$ is the intertemporal elasticity of substitution in consumption of the qth consumption service. The assumption embodied in (13), that utility of consumption is additively separable in the utility from $Q$ different consumption services, is restrictive but simplifies estimation considerably.

The household production function is a vector of Cobb-Douglas functions. That is, the qth consumption service is a Cobb-Douglas function of the stock of the qth consumption good and the shocks to preferences:

$$
\ln C_{t}^{q}=F_{q} \ln K_{t}^{q}+\sum_{s=1}^{S} G_{s}^{q} \ln X_{t}^{s} \quad q=1, \ldots, Q
$$

$F_{q}$ is the elasticity of the $q$ th consumption service with respect to $K_{t}^{q}$, and $G_{q}^{s}$ is the elasticity of the $q$ th consumption service with respect to the sth exogenous variable.

Imposing these assumptions about functional forms and the assumption of rational expectations implies that (8) and (10) simplify to

$$
\left.1=\beta\left(\frac{I_{t+1}^{q}}{I_{t}^{q}}\right)^{-1}\left(\left(\frac{I_{t+1}^{q}}{I_{t}^{q}}\right)\left(\frac{X_{t+1}^{1}}{X_{t}^{1}}\right)^{G_{1}^{q}} \ldots\left(\frac{X_{t+1}^{S}}{X_{t}^{S}}\right)^{G_{s}^{q}}\right)\right)^{1-\gamma_{q}}\left(1+r_{t+1}^{q}\right)+\epsilon_{t+1}
$$

and

$$
1=\beta\left(\frac{I_{t+1}^{q}}{K_{t}^{j}}\right)^{-1} \frac{\left(I_{t+1}^{q}\left(X_{t+1}^{1}\right)^{G_{1}^{q}} \ldots\left(X_{t+1}^{S}\right)^{G_{s}^{q}}\right)^{1-\gamma_{q}}}{\left(K_{t}^{q}\left(X_{t}^{1}\right)^{G_{1}^{j}} \ldots\left(X_{t}^{S}\right)^{G_{s}^{j}}\right)^{1-\gamma_{j}}}\left(1+r_{t+1}^{j, q}\right)+\nu_{t+1}
$$


The variables $\epsilon_{t+1}$ and $\nu_{t+1}$ are uncorrelated with all variables dated time $t$ or earlier by the assumption of rational expectations. The first order condition for purchases of a non-durable good determines the rate at which purchases of that good must grow relative to the growth rates of the exogenous variables and relative to real asset returns; the first order condition for durables determines the level of the stock of a durable relative to purchases of any non-durable and relative to the exogenous variables and real asset returns.

Equations (15) and (16) therefore say that, for an individual consumer, the time series properties of the variables $r_{t}^{q}, r_{t}^{j, q}$ and $X_{t}$ determine those of $I_{t}^{q}$ and $K_{t}^{j}$, up to serially uncorrelated error terms. The seasonality in an individual consumer's desired values of $I_{t}^{q}$ and $K_{t}^{j}$ can be the result of seasonality in preferences or seasonality in real asset returns.

Two additional comments about the model are in order. The seasonality of an individual consumer's income does not affect the seasonality of that consumer's consumption demands. To begin with, the seasonality of income is determined endogenously as the result of the consumer's optimal plan, since leisure may be one of the $Q$ consumption goods. In addition, even if labor income were exogenous, as it is in many treatments of the Life Cycle-Permanent Income model, ${ }^{18}$ the seasonality in this variable should have no effect on the optimal consumption plan. This is because the consumer takes account of all expected changes in future periods' income and achieves a consumption path that smooths them out by borrowing and lending. Changes in income produce changes in consumption only when there are revisions in the consumer's forecast of all future periods' income. These revisions errors should not be seasonal, however, by the very fact that they are revision errors.

The model is consistent with the stylized fact that there is more seasonal variation in purchases of durables than in purchases of non-durables and services. To see this, consider the special case where the preferences for services from the two types of goods are the same and there are no seasonals in preferences for either good. Then (16) reduces to

$$
1=\left(\frac{I_{t+1}^{q}}{K_{t}^{j}}\right)^{-\gamma}\left(1+r_{t+1}^{j, q}\right)+\nu_{t+1}
$$

Even if there were no seasonality in $r_{t}^{j, q}$, an individual consumer would still desire some in $K_{t}^{j}$ if there is any in $I_{t+1}^{q}$ (induced by a seasonal in $r_{t}^{q}$ ). Specifically, if desired $I_{t+1}^{q}$ is $x \%$ higher in a given season, then desired $K_{t}^{j}$ must be so also. But this means that desired purchases of the durable good must rise by more than $x \%$. Thus the presence of liquidity constraints is not necessary to explain the 'excess' seasonality of durables purchases. ${ }^{19}$

\section{B. Aggregation}

The existing empirical work on consumption, and the results to be presented below, estimate equations like (15) and (16) using aggregate per capita data. This procedure is appropriate under certain sets of conditions, the simplest of which is that all consumers are identical with respect to preferences and endowments so that (15) and (16) apply to every consumer and therefore trivially also to the aggregate per capita data. This set of conditions is not strictly necessary (see Rubinstein (1974)), but any set of conditions justifying the validity of (15) or (16) for the aggregate data involves strong assumptions. The reason for attempting to fit such a model, despite the clear violation of the necessary assumptions, is that if such a model were a reasonable approximation of the world it would be extremely useful because of its simpliticy. In the empirical work below, therefore, I

18 For example, Flavin (1981) and Bernanke (1985).

19 Mishkin (1976) proposes an explantion for the 'excess' volatility of durables based on the existence of liquidity constraints. 
assume that the necessary conditions presented in Rubinstein (1974) hold, so that (15) and (16) can be interpreted as applying to the aggregate per capita data.

The interpretations of the equations (15) and (16) given above for an individual consumer, however, do not follow when we think of them as applying to the aggregate data. In that case, there is no causal relation running from asset returns to consumption decisions; rather, the equilibrium values of both consumption and asset returns are determined simultaneously. The appropriate interpretation of (15) and (16) is then that they are equilibrium pricing functions of the type analyzed by Lucas (1978). These functions relate aggregate equilibrium consumption purchases and equilibrium expected asset returns to shocks to preferences and technology. The pricing functions impose restrictions on the joint distribution of consumption and asset returns but they do not restrict the process for consumption by itself.

In particular, therefore, the statement made above that, for an individual consumer, the seasonality of asset returns and preferences shocks determines the seasonality of consumption purchases, does not follow for the aggregate data. Rather, the appropriate interpretation of the seasonality in consumption is that the seasonality of shocks to the economy determines the seasonality of the joint process for consumption and asset returns. It is appropriate to ask what the seasonal pattern in consumption or asset returns would be if there were a different seasonal in preferences or technology, but not to say that the seasonality of asset returns causes the seasonality of consumption.

\section{Estimation and Results}

In this section I present estimates of the model described above for six non-durable goods and one durable good. The non-durable goods studied are Food, Fuel Oil and Coal, Gasoline and Oil, Housing Services, Electricity and Gas, and Transportation Services. The durable good is Motor Vehicles and Parts. These categories were selected because there are CPI components whose coverage matches closely that of the consumption category. ${ }^{20}$ The estimation was carried out on quarterly data. The sample period is 1948:1 to 1982:4, except for Fuel Oil and Coal and Electricity and Gas; for these goods the sample period is 1960:1 to 1982:4.

\section{A. Details of the Estimation Procedure}

The variables included in $X_{t}$ were a constant, time, time-squared, and seasonal dummies for quarters two, three and four. Specifically,

$$
\begin{aligned}
& X_{t}^{1}=1 \\
& X_{t}^{s}=\exp \left(d_{t}^{s}\right) \quad s=2,3,4 \\
& X_{t}^{5}=\exp (t) \\
& X_{t}^{6}=\exp \left(t^{2}\right)
\end{aligned}
$$

These assumptions about $X_{t}$ imply that equations (15) and (16) simplify to

$$
\begin{gathered}
1=\theta_{1}\left(\frac{I_{t+1}^{q}}{I_{t}^{q}}\right)^{-1}\left(\left(\frac{I_{t+1}^{q}}{I_{t}^{q}}\right) \exp \left(\sum_{s=2}^{4} G_{s}^{q}\left(d_{t+1}^{s}-d_{t}^{s}\right)+2 G_{6}^{q} t\right)\right)^{1-\gamma_{q}}\left(1+r_{t+1}^{q}\right)+\epsilon_{t+1} \\
1=\theta_{2} \exp \left(\sum_{s=2}^{4} \phi_{s} d_{t}^{s}+\phi_{5} t+\phi_{6} t^{2}\right)\left(\frac{I_{t+1}^{q}}{K_{t}^{j}}\right)^{-1} \frac{\left(I_{t+1}^{q}\right)^{1-\gamma_{q}}}{\left(K_{t}^{j}\right)^{1-\gamma_{j}}}\left(1+r_{t+1}^{j, q}\right)+\nu_{t+1}
\end{gathered}
$$

20 I have not included any estimates for Clothing and Shoes, even though there is a suitable deflator, for two reasons. First, it seems unreasonable to treat Clothing and Shoes as a non-durable. Second, no data on the stock of Clothing and Shoes exist. Therefore, the only way to estimate an equation for Clothing and Shoes is to create a stock series from the quarterly flow numbers. I have tried this but have been unable to obtain any sensible results. 
The parameter $\theta_{1}$ is a nonlinear function of $\beta$ and $G_{5}$. Neither of these parameters is separately identified by the model. The parameters $\theta_{2}$ and $\phi_{s}, s=2, \ldots, 6$, are nonlinear functions of $\beta, \gamma_{q}$, $\gamma_{j}$, and $G_{s}, s=2, \ldots, 6$. Only $\gamma_{q}$ and $\gamma_{j}$ are identified.

Equations (18) and (19) were estimated by two-stage nonlinear least squares ${ }^{21}$ with a constant, three seasonal dummies, time, time-squared and lagged values of the included variables used as instruments. Any variable dated time $t$ or earlier serves as a valid instrument since an implication of the model is that all such variables are uncorrelated with the error in the equation (Hansen (1982), Hansen and Singleton (1982)). ${ }^{22}$ There are cross equation restrictions on the system of equations (18) and (19), so the system can in principle be estimated more efficiently by a full information technique. In the estimation below I use single equation methods, however. This procedure has the advantage that misspecification in one equation will not affect the estimation of the other equation.

\section{B. Results}

Tables 2 and 3 present the main results. Table 2 displays estimates of equation (18) while Table 3 shows estimates of equation (19). There are six different specifications in each table, with each specification corresponding to a different non-durable.

The point estimates shown in Tables 2 and 3 are sensible and in most cases precise. The estimated values of the intertemporal elasticities of substitution have the theoretically correct sign in eleven out of twelve cases for non-durables and in all six cases for durables. In those cases where it is postive, the estimated value ranges from .015 to 1.706 for non-durables and from .474 to 1.357 for durables. The estimates therefore imply utility functions between linear and logarithmic in most cases. These values are in the range found in previous papers, although they are at the low end of that range. ${ }^{23}$

The coefficients on the seasonal dummies enter statistically significantly in most cases: a test of the hypothesis that the coefficients $G_{2}, G_{3}$, and $G_{4}$ are jointly equal to zero rejects that hypothesis for all goods except Electricity and Gas. In addition, the signs and magnitudes of the estimates are usually plausible. For example, the estimates for Fuel Oil and Coal indicate that a given size real purchase is more productive in the winter than in the summer, as one would expect. The estimates for Gasoline and Oil imply that purchases of this good are more productive in the summer than in the winter. This is plausible since bad weather makes driving a car undesirable in the winter in many parts of the country. The fact that the seasonal preference shocks are significantly different from zero means that inclusion of these shocks is necessary in order to explain the seasonal fluctuations in consumption and asset returns; these fluctuations are not entirely due to seasonal technology shocks.

Tables 3 and 4 also report results of tests of the overidentifying restriction on the model that any variable dated time $t$ or earlier should be uncorrelated with the error term. ${ }^{24}$ This is the restriction that previous papers have rejected. The tables show that the data never reject the

21 See Hansen (1982) and Hansen and Singleton (1982). One can also estimate linearized versions of (15) and (16), as in Hansen and Singleton (1983) and Mankiw (1983). I have chosen to estimate the nonlinear equations because in this model the linearized equations are still nonlinear in the parameters and so relatively little simplification is gained by employing the linearization.

22 See King and Garber (1983) for a critique of this approach.

23 Mankiw, Rotemberg, and Summers (1984) and Eichenbaum, Hansen and Singleton (1983) report values of $\gamma$ between 0 and 1; Hansen and Singleton (1983) report values between 0 and 2; Mankiw (1983) reports values between 2 and 4; and Hall (1982) reports values around 15.

24 The test statistic is Hansen's (1982) J-statistic. The test being carried out is whether the residual is correlated with the instruments; according to the model, the correlations should all be zero. Computationally, Runkle (1983) shows that under conditional homoskedasticity the J-statistic is identical to $T \times R^{2}$, where $T$ is the number of observations and $R^{2}$ is the $R^{2}$ from a regression of the residual series on the instruments. The $\mathrm{J}$-statistic is distributed as $\chi^{2}(q)$, where $q$ is the number of overidentifying restrictions. 
Table 2: Results of Estimation of Equation (18)

$\begin{array}{lcccccc} & \gamma & G_{2} & G_{3} & G_{4} & \text { Test Statistic } & \text { Significance Level } \\ \text { Food } & .107 & .016 & .016 & .009 & 15.18 & .126 \\ & (.87) & (1.66) & (1.60) & (.79) & & \\ \text { Gasoline and Oil } & .359 & .067 & .088 & .033 & 3.40 & .970 \\ & (1.87) & (1.21) & (1.26) & (1.05) & & \\ \text { Fuel Oil and Coal } & .050 & -.050 & -.060 & -.019 & 16.56 & .085 \\ & (1.49) & (2.42) & (2.45) & (1.76) & & .705 \\ \text { Housing } & 1.706 & -.004 & -.011 & -.004 & 7.21 & .195 \\ & (1.90) & (.94) & (1.22) & (.78) & & \\ \text { Electricity and Gas } & .015 & .000 & .004 & .001 & 13.54 & .031 \\ & (.07) & (.00) & (.04) & (.12) & & \\ \text { Transportation } & .179 & .005 & .010 & .001 & 19.82 & \end{array}$

Table 3: Results of Estimation of Equation (19)

$\begin{array}{lcccc} & \gamma_{j} & \gamma_{q} & \text { Test Statistic } & \text { Significance Level } \\ \text { Food } & 1.357 & .411 & 7.91 & .721 \\ & (1.15) & (1.15) & & \\ \text { Gasoline and Oil } & .657 & .381 & 7.62 & .747 \\ & (4.83) & (1.15) & & .634 \\ \text { Fuel Oil and Coal } & .761 & .459 & 8.87 & \\ & (5.92) & (1.36) & & .476 \\ \text { Housing } & .992 & .494 & 10.61 & .883 \\ & (4.86) & (1.45) & & \\ \text { Electricity and Gas } & .451 & -1.49 & 5.86 & .022 \\ & (6.14) & (.68) & & \\ \text { Transportation } & .474 & .083 & 22.39 & \end{array}$

Notes:

1. t-statistics in parentheses. 
overidentifying restrictions at the $99 \%$ level and only twice reject them at the $95 \%$ level. This is an unusual and encouraging result. It shows that in addition to providing plausible parameter estimates, the seasonally unadjusted data do not reject the model.

To check that the lack of rejection is due to the use of seasonally unadjusted data $I$ have estimated equations of the form (18) and (19) using seasonally adjusted data, with the seasonal dummies excluded. The results of this estimation are reported in Tables 4 and 5 . The estimates of $\gamma$ are negative more often with adjusted data than with unadjusted data. Moreover, the data reject the overidentifying restrictions on the adjusted data in eight out of twelve cases at the $99 \%$ level and in nine out of twelve cases at the $95 \%$ level.

The results presented in Tables 4 and 5, combined with those in Tables 2 and 3, demonstrate forcefully that the inclusion of seasonal fluctuations in the analysis above is the reason for the superior performance of the model presented here relative to previous results. The estimation strategy used in Tables 2-3 and 4-5 is identical, other than the treatment of seasonal fluctuations. Thus, the difference between the results is due to the treatment of seasonality and not to any other aspect of the model or estimation strategy employed. Although the estimation strategy employed in this paper involves many strong assumptions, such as the additively separability assumptions about preferences, all of these assumptions are also imposed in the estimations reported in Tables 4 and 5 using adjusted data. Comparison of the two sets of tables shows that the exclusion of seasonal fluctuations from analyses of the Life Cycle-Permanent Income model has been the key reason for the negative assessment of the model.

\section{The Effects of the Weather}

The results above show that there are quantitatively important shocks to preferences, but they do not provide any economic explanation for these shocks. In the remainder of this section I examine the hypothesis that the weather causes the seasonal preference shocks. To do this, I use two measures of the weather, in place of seasonal dummies, to re-estimate equation (18). ${ }^{25}$ Table 6 reports the results. The coefficient $G_{7}$ is the coefficient on a temperature variable and $G_{8}$ is that on a precipitation variable.

The results are generally good. The estimates of the intertemporal elasticity of substitution have the correct sign in five out of six cases. The temperature variable enters significantly in almost half the cases, and with a plausible sign, although the precipitation variable never enters significantly. The tests of the overidentifying restrictions do not reject the model in four out of six cases. To determine if the weather representation of the seasonal shocks is better than the seasonal dummy representation, I have estimated equation (18) including both the seasonal dummies and the weather variables and then tested the hypothesis that the coefficients on the weather variables are zero. The only good for which the data reject the null hypothesis is Electricity and Gas.

The conclusion to be drawn, then, is that the data are consistent with the hypothesis that seasonal shocks to preferences are caused by the weather; they do not, however, strongly suggest this hypothesis. It seems clear that the hypothesis deserves further consideration: since there is serial correlation in the weather it may have non-seasonal as well as seasonal affects, and since such

25 The weather data were constructed as follows. I obtained monthly data on temperature and precipitation for four U.S. cities: Los Angeles, New York, Chicago, and Atlanta. The temperature data give the mean temperature during the month, while the precipitation data are total precipitation over the month. The data were converted to a quarterly frequency by averaging the temperature data and summing the precipitation data. The quarterly series for the four cities were then averaged to obtain a national measure of temperature and precipitation. As a preliminary step, I regressed each of these variables on a constant, three seasonal dummies, and its own lagged values. The results showed, not suprisingly, that the weather is highly seasonal: most of the dummies enter significantly and with large coefficients. For example, the temperature variable is on average 31 degrees higher in summer than in winter. The results also show that there are non-seasonal movements in the weather variables since the first autoregressive parameter enters significantly in both cases. This is important to have if the use of weather variables is to improve on the use of seasonal dummies. 
Table 4: Results of Estimation of Equation (18) Using Seasonally Adjusted Data

$\begin{array}{lccc} & \gamma & \text { Test Statistic } & \text { Significance Level } \\ \text { Food } & .496 & 40.88 & .000 \\ & (1.67) & & .000 \\ \text { Gasoline and Oil } & 1.458 & 29.66 & \\ & (3.26) & & .525 \\ \text { Fuel Oil and Coal } & .986 & 6.13 & \\ & (3.03) & & .000 \\ \text { Housing } & -.605 & 58.90 & .046 \\ & (2.19) & & \\ \text { Electricity and Gas } & -.095 & 14.32 & .000 \\ & (.76) & & \\ \text { Transportation } & .762 & 29.25 & \end{array}$

Table 5: Results of Estimation of Equation (19) Using Seasonally Adjusted Data

$\begin{array}{lcccc} & \gamma_{j} & \gamma_{q} & \text { Test Statistic } & \text { Significance Level } \\ \text { Food } & -.013 & 4.438 & 24.77 & .002 \\ & (.19) & (17.68) & & .800 \\ \text { Gasoline and Oil } & .043 & .861 & 4.59 & \\ & (.75) & (22.43) & & .000 \\ \text { Fuel Oil and Coal } & -.057 & .834 & 35.49 & \\ & (.81) & (12.27) & . & .366 \\ \text { Housing } & .065 & 1.565 & 8.73 & .006 \\ & (1.12) & (19.12) & & \\ \text { Electricity and Gas } & -.057 & .755 & 21.27 & .003 \\ & (1.18) & (12.50) & & \\ \text { Transportation } & -.041 & .775 & 23.15 & \end{array}$

Notes:

1. t-statistics in parentheses. 
Table 6: Results of Estimation of Equation (18) Using Weather Variables

$\begin{array}{lccccc} & \gamma_{q} & G_{5} & G_{6} & \text { Test Statistic } & \text { Significance Level } \\ \text { Food } & .099 & .027 & -.013 & 5.89 & .881 \\ & (2.23) & (4.55) & (.95) & & \\ \text { Gasoline and Oil } & .309 & .132 & .019 & 6.48 & .839 \\ & (1.99) & (1.54) & (.54) & & \\ \text { Fuel Oil and Coal } & .033 & -.085 & .009 & 17.01 & .108 \\ & (1.05) & (1.89) & (.31) & & .001 \\ \text { Housing } & .775 & .020 & -.002 & 30.58 & \\ & (2.41) & (.47) & (.11) & & .003 \\ \text { Electricity and Gas } & -.039 & .036 & -.007 & 28.25 & .107 \\ & (1.55) & (2.10) & (.67) & & \\ \text { Transportation } & .185 & .022 & .003 & 17.02 & \end{array}$

Notes:

1. t-statistics in parentheses. 
shocks are real, they are consistent with real business cycle models. It also seems clear, however, that it will be difficult to separate the effects of the weather from other seasonal effects using aggregate data. ${ }^{26}$

\section{Seasonal Fluctuations and Equilibrium Models of Consumption}

The results presented above show that the fluctuations in aggregate consumption are consistent with an equilibrium model of consumption behavior. This result is the opposite of that obtained in previous papers, and as discussed above, it is due to the inclusion of seasonal fluctuations in the analysis. The fact that including seasonal fluctuations gives a more optimistic view of equilibrium models is not suprising; since seasonal fluctuations are predictable, it is likely that agents anticipate them and adjust their behavior accordingly, even if they cannot do the same with business cycle fluctuations. Yet most economic analysis of equilibrium models has been carried out with seasonally adjusted or annual data and therefore includes a bias towards rejecting the equilibrium view. It is therefore important to the assessment of equilibrium models that economic analyses consider the seasonal fluctuations in other aspects of the economy.

26 Roll (1984) provides an interesting demonstration of the effects of the weather on the price of orange juice. 


\section{References}

Ando, Albert and Franco Modigliani (1963), "The Life Cycle Hypothesis of Saving: Aggregate Implications and Tests," American Economic Review, 53, 1(Mar.), 55-84.

Bernanke, Ben S. (1982), "Adjustment Cost, Durables, and Aggregate Consumption," NBER WP \#1038.

(1984), "Permanent Income, Liquidity, and Expenditure on Automobiles: Evidence From Panel Data," Quarterly Journal of Economics, 99, 3(Aug.), 587-614.

Browning, M. J. (1983), "A Non-Parameteric Test of the Life Cycle, Rational Expectations Hypothesis," Discussion Paper \# 83/135, University of Bristol.

Davidson, J.E.H. and D.F. Hendry (1981), "Interpreting Econometric Evidence: The Behaviour of Consumers' Expenditure in the United Kingdom," European Economic Review, 16, 177-92.

Davidson, J.E.H., D.F. Hendry, F. Srba, and S. Yeo (1978), "Econometric Modelling of the Aggregate Time Series Relationship Between Consumers' Expenditures and Income in the United Kingdom," Economic Journal, 88, 661-92.

Eichenbaum, Martin S. and Lars Peter Hansen (1983), "Uncertainty, Aggregation and the Dynamic Demand for Consumption Goods," manuscript, Carnegie-Mellon University.

Eichenbaum, Martin S., Lars Peter Hansen and Kenneth J. Singleton (1984), "A Time Series Analysis of Representative Agent Models of Consumption and Leisure Choice Under Uncertainty," manuscript, Carnegie-Mellon University.

Eichenbaum, Martin S., Lars P. Hansen, and Scott Richard (1985), "Dynamic Equilibrium Pricing of Durable Goods," manuscript, Graduate School of Industrial Administration, CarnegieMellon University.

Flavin, Marjorie (1981), "The Adjustment of Consumption to Changing Expectations About Future Income," Journal of Political Economy, 89, 5(Oct.), 974-1009.

Friedman, Milton (1957), A Theory of the Consumption Function, Princeton, N.J.: Princeton University Press.

Grossman, Sanford J. and Robert Shiller (1981), "The Determinants of the Variability of Stock Market Prices," American Economic Review, 71, 2(May), 222-7.

Hall, Robert E. (1978), "Stochastic Implications of the Life Cycle-Permanent Income Hypothesis: Theory and Evidence," Journal of Political Economy, 86, 6(Dec.), 971-87.

(1981), "Intertemporal Substitution in Consumption," NBER WP \# 720.

Hall, Robert E. and Frederic S. Mishkin (1982), "The Sensitivity of Consumption to Transitory Income: Estimates from Panel Data on Households," Econometrica, 50, 2(April), 461-481.

Hansen, Lars Peter (1982), "Large Sample Properties of Generalized Method of Moments Estimators," Econometrica, 50, 4(July), 1029-54.

Hansen, Lars Peter and Kenneth J. Singleton (1982), "Generalized Instrumental Variables Estimation of Nonlinear Rational Expectations Models," Econometrica, 50, 5(Sept.), 1269-86.

(1983), "Stochastic Consumption, Risk Aversion, and the Temporal Behavior of Asset Market Returns," Journal of Political Economy, 91, 2(April), 249-65.

Hayashi, Fumio (1982), "The Permanent Income Hypothesis: Estimation and Testing By Instrumental Variables," Journal of Political Economy, 90, 5(Oct.), 895-918.

(1984), "The Permanent Income Hypothesis and Consumption Durability: Analysis Based on Japanese Panel Data," NBER. 
Heien, Dale (1983), "Seasonality in U.S. Consumer Demand," Journal of Business and Economic Statistics, 1, 4(Oct.), 280-84.

Hendry, D.F. and T. Von Ungern-Sternberg (1980), "Liquidity and Inflation Effects on Consumers' Expenditures," in Angus S. Deaton, ed., Essays in the Theory and Measurement of Consumers' Behaviour, Cambridge: Cambridge University Press.

King, Robert and Peter Garber (1983), "Deep Structural Excavation? A Critique of Euler Equation Methods," NBER Technical WP \# 31.

King, Mervyn A. (1983), "The Economics of Savings," NBER WP \# 1247.

Lancaster, Kelvin J. (1966), “A New Approach to Consumer Theory,” Journal of Political Economy, 74, 2(Apr.), 132-57.

Mankiw, N. Gregory (1982), "Hall's Consumption Hypothesis and Durable Goods," Journal of Monetary Economics, 10, 417-25.

(1983), "Consumer Durables and the Real Interest Rate," NBER WP \# 1148.

Mankiw, N. Gregory, Julio Rotemberg and Lawrence H. Summers (1984), "Intertemporal Substitution in Macroeconomics," Quarterly Journal of Economics, forthcoming.

Miron, Jeffrey A. (1984), "The Seasonal Fluctuations in Consumption and Labor Supply," Chapter V of The Economics of Seasonal Time Series, Ph.D. Thesis, M.I.T.

Mishkin, Frederic S. (1976), "Illiquidity, Consumer Durable Expenditure, and Monetary Policy," American Economic Review, 66, 4(Sept.), 642-54.

Modigliani, Franco and Richard Brumberg (1954), "Utility Analysis and the Consumption Function: An Interpretation of Cross-Section Data," in K. Kurihara, ed., Post-Keynesian Economics, Rutgers University Press, New Brunswick.

Nelson, Charles R. and Charles I. Plosser (1982), "Trends and Random Walks in Macroeconomic Time Series: Some Evidence and Implications," Journal of Monetary Economics, 10, 2(Sept.), 139-62.

Roll, Richard (1984), "Orange Juice and the Weather," American Economic Review, 74, 5(Dec.), 861-80.

Rubinstein, Mark (1974), "An Aggregation Theorem for Securities Markets," Journal of Financial Economics, 1, 3(Sept.), 225-44.

Runkle, David (1983), "Liquidity Constraints and the Permanent Income Hypothesis: Evidence from Panel Data," in Essays in Empirical Macroeconomics, Ph.D. Thesis, M.I.T.

Sargent, Thomas (1978), "Rational Expectations, Econometeric Exogeneity and Consumption," Journal of Political Economy, 86, 4(Aug.), 673-700.

Shapiro, Matthew D. (1984), "The Permanent Income Hypothesis and the Real Interest Rate: Some Evidence from Panel Data," Economic Letters, 14, 93-100.

Shiller, Robert (1982), "Consumption, Asset Markets, and Macroeconomic Fluctuations," in Economic Policy in a World of Change, Carnegie-Rochester Conference Series, 17, 203-38.

White, Halbert (1980), “A Heteroscedasticity-Consistent Covariance Estimator and A Direct Test for Heteroscedasticity," Econometrica, 48, 817-38. 


\section{Appendix A \\ Construction of Seasonally Unadjusted Data on Real Consumption Purchases}

The Bureau of Economic Analysis of the Department of Commerce (BEA) constructs and publishes the data in the National Income and Product Accounts on consumption purchases. The BEA does not provide any seasonally unadjusted data on real consumption purchases, however, so in order to obtain such data it is necessary to construct them. This can be done as follows.

The BEA does construct seasonally unadjusted data on the nominal value of consumption purchases. These data are published on a quarterly basis in the Survey of Current Business. The categories of consumption for which these data are available are listed in Table A1, along with the dates of availability and the share of each category in total consumption. There are thirteen categories, which includes three different categories of durable goods, five of non-durables, and five of services. Most of the series are available starting in 1946:1, although a few begin only in 1959:1.

The Bureau of Labor Statistics publishes seasonally unadjusted data on the detailed components of the Consumer Price Index in the Monthly Labor Review. Table A1 also shows the CPI components that match most closely the thirteen categories of consumption purchases. In some cases the link between the definition of the consumption category and the CPI component is close (e.g. Food, Gasoline and Oil, and Fuel Oil and Coal) but for others it is rather poor (Furniture and Appliances, Other Durables, Other Non-Durables).

Seasonally unadjusted data on real consumption purchases can be constructed by dividing the seasonally unadjusted data on nominal consumption purchases by the seasonally unadjusted components of the CPI. This procedure is analagous to the one used by BEA to create seasonally adjusted data on consumption purchases, since BEA's practice is to divide seasonally adjusted data on nominal purchases by a seasonally adjusted component of the CPI. The validity of the procedure (with adjusted or unadjusted data) depends on how well the categories for which CPI components exist match up with the categories for which the data on nominal consumption purchases exist.

I have used the data for the CPI components shown in Table A1 to deflate the data on the thirteen categories of nominal consumption purchases shown in the table. These are the data used above to construct stylized facts and to estimate the model of consumption behavior. 
Table A1: Availability of Seasonally Unadjusted Consumption Data

\begin{tabular}{|c|c|c|c|}
\hline Consumption Category & CPI Component & Dates Available & Share (\%) \\
\hline Consumption & All Items & 1946:1-1982:4 & 100.0 \\
\hline Durables & Durables & $1946: 1-1982: 4$ & 12.3 \\
\hline Motor Vehicles and Parts & New Cars & 1946:1-1982:4 & 5.4 \\
\hline Furniture and Appliances & Household Furniture & 1946:1-1982:4 & 4.7 \\
\hline Other Durables & Bicycles & $1946: 1-1982: 4$ & 2.2 \\
\hline Non-Durables & Non-Durables & 1946:1-1982:4 & 38.7 \\
\hline Food & Food & 1946:1-1982:4 & 20.2 \\
\hline Clothing and Shoes & Apparel Commodities & 1946:1-1982:4 & 6.0 \\
\hline Gasoline and Oil & Gas, Oil, and Coolant & 1946:1-1982:4 & 4.8 \\
\hline Fuel Oil and Coal & Fuel Oil and Coal & 1959:1-1982:4 & .9 \\
\hline Other Non-durables & Housekeeping Supplies & 1959:1-1982:4 & 6.8 \\
\hline Services & Services & 1946:1-1982:4 & 49.0 \\
\hline Housing & Rent & 1946:1-1982:4 & 16.5 \\
\hline Household Operation & Housekeeping & 1946:1-1982:4 & 7.3 \\
\hline Electricity and Gas & Electricity & 1959:1-1982:4 & 3.8 \\
\hline Other Household Operation & Housekeeping & 1959:1-1982:4 & 3.5 \\
\hline Transportation & Transportation Services & 1946:1-1982:4 & 3.6 \\
\hline Other Services & Other Services & 1946:1-1982:4 & 21.7 \\
\hline
\end{tabular}

